\title{
O FILME "ALEX STRANGELOVE" COMO RECURSO PEDAGÓGICO PARA A FORMAÇÃO EM EDUCAÇÃO SEXUAL
}

\author{
THE FILM “ALEX STRANGELOVE” AS A PEDAGOGICAL RESOURCE \\ FOR TRAINING IN SEXUAL EDUCATION
}

\author{
Ana Regina Branco de Miranda \\ Mestranda \\ Universidade Estadual Paulista -Fclar - UNESP \\ Araraquara, São Paulo - Brasil \\ arbmiranda@yahoo.com.br \\ Prof. Dr. Ricardo Desidério da Silva \\ Doutor \\ Universidade Estadual do Paraná - UNESPAR \\ Apucarana, Paraná - Brasil \\ contatodesiderio@hotmail.com
}

Resumo: Este artigo tem por objetivo propor uma reflexão a partir do filme "Alex Strangelove", disponível na plataforma Netflix, de modo a promover debates e reflexões frente à temática da diversidade sexual no processo de formação docente, principalmente a partir da utilização de vídeos como recursos pedagógicos eficazes para inserção do tema. Tal estudo se caracteriza por uma pesquisa qualitativa, do tipo documental, a partir da perspectiva da educação audiovisual da sexualidade desenvolvida por Silva $(2015,2020)$, que estabelece uma proposta metodológica de análise ao estudo de imagens e sons. Contudo, verifica-se que o filme problematiza questões da diversidade sexual, possibilitando o pensar sobre a homossexualidade para além de uma escolha sexual, podendo ainda trazer novos direcionamentos para sua utilização como material educativo na escola.

Palavras-chave: homossexualidade; sexualidade; educação audiovisual.

Abstract: This article aims to propose a reflection from the film "Alex Strangelove", available on the Netflix platform, in order to promote debates and reflections on the theme of sexual diversity in the process of teacher education, mainly from the use of videos as resources effective pedagogical approaches to insert the theme. Such a study is characterized by a qualitative research, of documentary type, from the perspective of audiovisual education of sexuality developed by Silva $(2015,2020)$, which establishes a methodological proposal of analysis to the study of images and sounds. However, it appears that the film problematizes issues of sexual diversity, making it possible to think about homosexuality in addition to a sexual choice, and may also bring new directions for its use as educational material at school.

Keywords: homosexuality; sexuality; audiovisual education.

Para citar - ABNT NBR 6023:2018

MIRANDA, Ana Regina Branco de; SILVA, Prof. Dr. Ricardo Desidério da. O filme “Alex Strangelove” como recurso pedagógico para a formação em educação sexual. Cadernos de Pós-graduação, São Paulo, v. 20, n. 1, p. 53-64, jan./jun. 2021. Disponível em:

https://doi.org/10.5585/cpg.v20n1.19740. 
Introdução

Abordar as questões relacionadas à temática da sexualidade ainda não é uma tarefa fácil, uma vez que somos pertencentes a uma sociedade repleta de tabus e preconceitos, marcados por uma cultura conservadora e, como nos aponta Kipnisi (2012), “[...] vivemos em uma época sexualmente interessante, o que significa uma cultura que consegue ser ao mesmo tempo hipersexualizada e conservar suas esporas puritanas em proporções exatamente iguais” (p. 20). Esses paradoxos acabam dificultando o processo de ensino e aprendizagem na mediação professor/aluno cotidianamente.

No entanto, pensar a escola enquanto espaço de produção de cultura é almejar uma proposta eficaz em que haja objetivos, conteúdos pertinentes e metodologias adequadas, como a utilização de filmes, por exemplo, visto que são recursos pedagógicos e proporcionam debates sobre a temática (SILVA, 2015; 2020).

Deste modo, segundo o mesmo autor, se pensarmos na educação e nos meios de comunicação de massas como áreas distintas, pode-se observar que ambos "lidam com os objetos culturais de formas diferentes. Este fator se deve principalmente a uma dificuldade do educador (escola) em se aproximar e enfrentar esses objetos audiovisuais (cultura), como se cultura e escola pudessem ser divididas" (SILVA, 2020, p.355).

Nestes termos, nota-se a eficácia em utilizar objetos audiovisuais para que se efetive a Educação Sexual. "É certo que a função do professor deve ser a de polemizar, lidar com valores, tabus, preconceitos e informar sobre dúvidas, e não somente transmitir o conteúdo biológico da sexualidade" (FIGUEIRÓ, 2014, p 19). Promover um espaço de reflexões aos alunos, onde possam dialogar, questionar e se expressar, sem serem criticados ou depreciados, é fundamental. E o filme abre esse canal de comunicação para que professores e alunos dialoguem sobre a temática.

Portanto, este artigo tem como objetivo propor uma reflexão a partir do filme "Alex Strangelove", disponibilizado na plataforma global de filmes e séries da empresa Netflix, dado que a produção é uma importante ferramenta na formação inicial de alunos do curso de Pedagogia, promovendo e problematizando reflexões sobre a temática homossexualidade.

\section{Formação docente: a efetivação da Educação Sexual}

Planejar ações que envolvam projetos de Educação Sexual na escola não é algo simples, pois além do simples desejo da ação, é necessária uma preparação específica do professor - uma formação inicial e continuada. De acordo com Silva (2015, p. 20), 
a Educação Sexual na escola é hoje uma necessidade a ser efetivada tanto nas discussões políticas, quanto nas ações e concretização de sua prática. Ao dizer Educação Sexual estamos nos referindo a toda ação continua, em um processo de interação humana pelo qual, inserido em uma cultura, uma história e uma política, nos leva a pensar na construção de um sujeito ativo frente às informações, aos desejos, às necessidades básicas sobre seu corpo, seu funcionamento e organização. Assim, tal sujeito pode dialogar, ter voz ativa e poder expressar suas opiniões, respeitando as opiniões do outro e significativamente percebendo a sexualidade como algo positivo em sua vida, sem medos, tabus e/ou receios em poder/querer aprender sobre tudo que se passa a sua volta durante toda sua vida.

No entanto, segundo Figueiró (2014), a Educação Sexual na escola deve ainda promover uma visão positiva da sexualidade, desenvolvendo uma melhor relação interpessoal, através de um pensamento crítico, sabendo respeitar e compreender a si e ao outro, além de preparar o aluno para a tomada de decisões responsáveis a respeito de sua vida sexual. Para isso, o professor deve se pautar em uma Educação Sexual de forma humanizadora, sendo um mediador de esperanças e projetos de vida (FIGUEIRÓ, 2014).

A formação dos professores contribui para a vivência da sexualidade com respeito e sem discriminação. Através de capacitação dos profissionais da educação, são proporcionados momentos de análise, reflexão e interação que podem levar os alunos a interagir com seus pares e formar opiniões saudáveis sobre sexualidade, gênero e diversidade sexual (RODRIGUES \& SALLES, 2011). A falta de formação dos professores dificulta o desenvolvimento da Educação Sexual na escola que, por sua vez, prejudica os alunos, pois não lhes é possibilitado no ambiente escolar um espaço em que possam manifestar livremente suas dúvidas e curiosidades (LEÃO, 2009).

Os currículos das licenciaturas ainda são pobres em conteúdos que se relacionem à sexualidade, gênero e diversidade sexual. Segundo Leão (2009), a formação do professor deve percorrer os cursos de formação inicial e se estender por todos os períodos de exercício profissional ao longo da carreira, através da formação continuada. E essa formação continuada refere-se às propostas ou ações, tais como cursos, estudos e reflexões voltados para aprimorar a prática profissional do professor (FIGUEIRÓ, 2014).

Para que o trabalho de Educação Sexual na escola se efetive, é importante que tenha um caráter pedagógico, ou seja, o professor poderá identificar em que momento abordará alguns conteúdos de forma sistemática e planejada. Assim, o professor deve se utilizar de um espaço para que, através de dinâmicas, projetos, vivências, dramatizações, possa problematizar, levantar questionamentos e ampliar a visão de mundo e de conhecimento com relação à sexualidade, discutindo os tabus, crenças, preconceitos e atitudes da sociedade. Diante desse cenário, o papel do professor se revela mais como um provocador de ideias do que um expositor de matérias. Esses métodos valorizam o diálogo, o autoconhecimento e a integração entre pensar, sentir e agir, criando um ambiente de confiança e de reflexão (FIGUEIRÓ, 2018). 
Mas é evidente que os modelos a serem utilizados pelos professores ainda remetem ao passado e a utilização de novas estratégias e tecnologias para levar melhorias e aperfeiçoamentos às suas aulas traz insegurança e medo.

\footnotetext{
Quando nós educadores adentramos a ambiência da escola, entramos em contato com algo que há séculos possui o mesmo formato. A cultura oral permeia a sala de aula, espaço onde imperam as palavras escrita e falada, sob a capa da disciplina, do controle, das políticas que ditam, entre outras coisas, como se deve se comportar em sociedade, principalmente em relação à sexualidade (SILVA, 2015, p. 21).
}

Nota-se que, para a formação em sexualidade, é possível utilizar vários recursos, por meio dos quais os professores se apossam de conhecimentos e técnicas que os empoderam na discussão da temática, deixando-os livres de tabus e preconceitos, através de uma visão mais positiva da sexualidade.

Contudo, a finalidade da Educação Sexual na escola é contribuir para que o aluno desenvolva e exerça sua sexualidade com prazer e responsabilidade, através de um trabalho com atividades sistemáticas, planejadas, contínuas e que envolvam, além de toda comunidade escolar, os pais desses alunos. É através da prevenção que se protege as crianças, as quais passam por várias transformações corporais, hormonais, psíquicas, e que devem ser acompanhadas. Ora, nada mais plausível que formar professores que saibam mediar todos os temas que rodeiam seus alunos.

Sendo assim, é evidente que a abordagem emancipatória proposta por Figueiró (2014) seja a melhor estratégia, pois concebe a Educação Sexual como um caminho para preparar o educando para viver a sexualidade de forma positiva, saudável e feliz e, sobretudo, para formá-lo como cidadão consciente, crítico e engajado nas transformações de todas as questões sociais ligadas direta ou indiretamente à sexualidade.

Para isso, a formação do professor é necessária. Afinal, essa formação é que permitirá a ele ter subsídios que norteiam essa mediação. Segundo Leão (2009), a formação do professor deve percorrer os cursos de formação inicial e se estender por todos os períodos de exercício profissional ao longo da carreira, através da formação continuada. Para Figueiró (2014, p.105) “essa formação continuada refere-se às propostas ou ações, tais como cursos, estudos e reflexões voltados para aprimorar a prática profissional do professor".

No entanto, pensar numa aproximação do uso de vídeos para essa formação nos leva refletir, como aponta Silva (2020), que a educação e os meios de comunicação de massas como áreas distintas podem ser observadas como algo que lidam com os objetos culturais de formas diferentes. Para o autor, "este fator se deve principalmente a uma dificuldade do educador (escola) em se aproximar e enfrentar esses objetos audiovisuais (cultura), como se cultura e escola pudessem ser divididas" (SILVA, 2020, p. 355). 
Louro (2008) também corrobora com essa visão quando diz que os filmes exercitam pedagogias culturais através do poder de sedução e autoridade, exercendo pedagogias da sexualidade sobre quem os assiste.

Com isso, "o vídeo para fins educativos pode sim contribuir, e muito, para reflexões importantes sobre diversas temáticas no âmbito educacional, possibilitando ainda o poder fazer-se cultura" (SILVA, 2020, p.359).

\section{Método}

Este estudo é caracterizado por uma pesquisa qualitativa, do tipo documental, que teve por objetivo analisar o filme "Alex Strangelove", da plataforma digital Netflix. O presente artigo apresenta reflexões sob a temática da homossexualidade, parte integrante das discussões do filme, a partir da perspectiva da educação audiovisual da sexualidade desenvolvida por Silva $(2015,2020)$, que estabelece uma proposta metodológica de análise ao estudo de imagens e sons, "partindo de uma cultura audiovisual (iniciada com o cinema, passando pela televisão até as novas tecnologias da cultura do upload) que nos leve a compreensão das diferenças e aproximações de linguagens entre o vídeo e o cinema, assim como a pedagogia do vídeo e seus fins educativos" (SILVA, 2020, p.355).

\section{Resultados e discussão}

\section{Descrição do material}

Lançado em 2018, o filme "Alex Strangelove" passou a ser disponibilizado na plataforma de vídeo supracitada a partir do dia 8 de junho do mesmo ano, data bastante oportuna pela proximidade ao dia dos namorados. O filme se passa nos dias atuais e a escola é o local central da maior parte da trama.

Quadro 1 - Informações sobre o filme

\begin{tabular}{|l|l|}
\hline \multicolumn{1}{|c|}{ Vídeo } & \multicolumn{1}{c|}{ Alex Strangelove } \\
\hline Tema central & Igualdade de gênero \\
\hline Sinopse & $\begin{array}{l}\text { Alex Truelove (Daniel Doheny) é um aluno exemplar do último ano do En- } \\
\text { sino Médio. Ele tem um grande futuro pela frente, mas antes de se formar } \\
\text { ele quer alcançar o último marco da adolescência: perder a virgindade com } \\
\text { a sua namorada, Claire (Madeline Weinstein). Tudo se complica quando ele } \\
\text { conhece Elliot (Antonio Marziale), um charmoso menino gay que sem que- } \\
\text { rer põe Alex em uma jornada de autodescoberta. }\end{array}$ \\
\hline $\begin{array}{l}\text { Personagem(ns) } \\
\text { principal (is) }\end{array}$ & Alex Truelove, Claire e Elliot \\
\hline Contexto & Virgindade, homossexualidade. \\
\hline Duração & 99 min. \\
\hline
\end{tabular}

Fonte: os autores. Estrutura proposta por SILVA (2015). 


\section{O filme “Alex Strangelove”}

Fernando (2018) descreve que o filme se propõe narrar a história de um jovem que está tentando perder a virgindade com sua namorada, sua melhor amiga do colegial, inclusive. Alex é nerd, presidente do grêmio e uma referência para todos a sua volta, o que, nem de longe, pesa para ele durante sua trajetória no filme. No entanto, nessa busca por perder a virgindade, busca essa que surge a partir do momento em que ele e sua namorada Claire acreditam ser necessário avançar mais uma etapa na vida amorosa de ambos, Alex conhece Elliot por acaso, um gay assumido que partilha de sua liberdade com todos abertamente. Após se conhecerem, tudo começa a mudar dentro de Alex, mas, na verdade, o interessante é observar que isso desperta em Alex alguns questionamentos sobre a sua própria sexualidade (FERNANDO, 2018).

Para o autor, o que se destaca no filme é a temática tratada com simplicidade, pois

as questões sociais dos personagens de uma maneira até cômica, mas nada desrespeitosa como já estamos saturados de ver em besteirol americano desde os anos 90 . Aqui não só a sexualidade de Elliot e Alex são postas na mesa e desconstruídas, mas questões como as de peso, cor e etnia passam até despercebidas para que possamos então entender que o plural está tão presente entre eles que tanto faz, não precisamos usar o exterior de cada um para separá-los, mas sim suas personalidades é que contam e marcam território (FERNANDO, 2018, s/p).

Neste sentido, Silva (2015) nos afirma que,

assim como o cinema, a família, os amigos, a cidade, a escola, a igreja e a própria mídia, os vídeos possibilitam, através de sua projeção oral e figurativa das coisas, uma educação por meio dos valores atribuídos a cada uma dessas coisas que são/estão inseridas no mundo, o que nos permite apreender suas características mais detalhadas e importantes (SILVA, 2015, p. 45-46)

Diante do exposto, o filme é um artefato cultural que possibilita ao espectador um envolvimento com a trama, refletindo e incitando uma discussão sobre cada tema em questão, sendo um recurso pedagógico rico para atingir todas as etapas do conhecimento, ampliando as possibilidades de estabelecer relações para pensar de outro modo o presente que se vive (FISCHER, 2007).

E para a autora, 
apostar que há um emaranhado rico de práticas, envolvendo toda uma tecnologia de produção de imagens, modos diferenciados de recepção e apropriação de narrativas audiovisuais, é apostar na análise das mídias como elementos fundamentais da cultura contemporânea. Significa também arriscar a pensar que há um sem-número de materiais audiovisuais, do cinema, do vídeo e da televisão, em que as escolhas éticas e estéticas dos criadores se pautam pelas incertezas da linguagem, pelo não fechamento das interpretações, pelas pequenas cintilações de uma obra aberta, disponível a um criativo gesto educacional (FISCHER, 2007, p. 298).

Pensando no ambiente escolar, o filme, quando utilizado como meio educativo, e qualquer que seja seu gênero, demonstra que "nosso papel é possibilitar não apenas as reflexões do que já foi pensado/apresentado no material, mas ensinar o aluno a pensar por si só, ressignificando o que foi apresentado, atribuindo assim ao material novos sentidos e novas concepções" (SILVA, 2020, p. 367).

Diante disso, o filme "Alex Strangelove" versa sobre a temática central da homossexualidade na vivência da adolescência, uma temática necessária de ser trabalhada na formação inicial do curso de Pedagogia. Sendo a formação em Educação Sexual de fundamental importância para professores da educação básica, o filme, assim como sua análise, reflexões e problematizações, traz aos graduandos uma visão mais amorosa e natural da sexualidade, descaracterizando a ideia de opção sexual, como se a atração afetivo-sexual fosse passível de escolha. No filme, um diálogo importante que evidencia essa não escolha em ser heterossexual, bissexual ou homossexual está no diálogo entre Alex e Elliot:

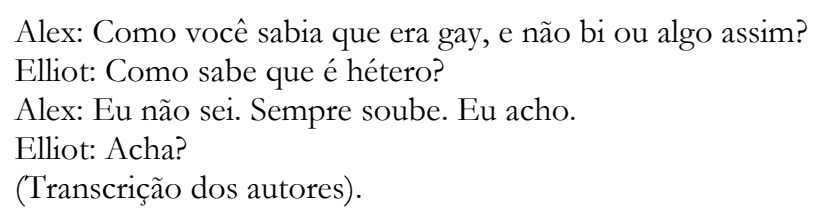

No entanto, nem sempre sua abordagem é simples, pois ainda se nota que a "sexualidade na escola possui o foco numa perspectiva biológica, restringindo o espaço educativo a uma visão heteronormativa da sexualidade" (NASCIMENTO E CHIARADIA, 2017, p. 106), postulando que a orientação sexual aceita é a heterossexual, ignorando a homossexualidade e a bissexualidade.

"Essa afirmação da heteronormatividade busca um estado de equilíbrio sobre a espécie humana, estabelecendo que o correto é a procriação e continuidade da espécie, fazendo com que os que não se enquadram nesse modelo, sintam-se anormais" (NASCIMENTO E CHIARADIA, 2017, P. 107).

Corroborando os autores Silva (2015) e Figueiró (2014), o desejo sexual não se dá dessa forma normativa. A busca ao objeto erótico, ou seja, a orientação sexual de um indivíduo, se dá de diversas formas: heterossexual, homossexual, bissexual. E isso não os torna anormais, doentes, 
pecaminosos ou promíscuos na sua identidade sexual. "Romper com essa visão naturalizada da heteronormatividade faz com que os professores desnudem o cotidiano escolar em outra óptica que os faça perceber as práticas sexistas, homofóbicas e machistas" (MOTTA E NUNES, 2016 p. 15); proporcionando reflexões, investigações e reconstruções de uma sexualidade inerente ao ser humano.

Assim, seria possível, como afirma Motta e Nunes (2016), construir uma educação não sexista, não homofóbica e não machista em que meninos e meninas sejam educados como seres humanos, assumindo suas características afetivas, sensoriais e cognitivas.

Porém, nos deparamos com esses papéis sexuais desde muito cedo, a começar pela própria família que estipula o sistema binário masculino e feminino; e torna a homossexualidade desalojada desse eixo, afirma Barbosa (2018). Além disso, reitera que a homossexualidade já foi vista como desajuste sexual, sendo até classificada como doença em tempos atrás. Propor a heterossexualidade como hegemonia exclui a homossexualidade através de um sistema de proibições.

O filme analisado retrata essa hegemonia quando os adolescentes utilizam o "ser gay" por qualquer atitude que fuja dos padrões considerados normativos. Com isso nota-se, conforme apontam Nascimento e Scorsolini-Comin (2018), que a família tem uma grande influência na sexualidade de seus filhos, tornando a revelação da orientação sexual como um processo conflituoso, negando a realidade, causando diversas dificuldades ao homossexual, como a busca por apoio e aceitação.

No filme, percebe-se essa atuação da família na cena em que Elliot conta sobre sua homossexualidade e seus pais o expulsam de casa, fazendo com que ele vá morar na casa de uma amiga. Percebe-se, assim, que a família também vive nessa era da heteronormatividade, repleta de preconceitos, tabus e mitos quanto à sexualidade. Isso acaba provocando um choque inicial, fazendo com que a família negue a realidade, proporcionando ao homossexual um período de intensa luta interna, gerando sentimentos de negação, culpabilização, medo, revolta, vergonha (NASCIMENTO; SCORSOLINI-COMIN, 2018).

Em momentos mais antigos, a homossexualidade era tratada como gays afetados em seus personagens. Hoje contamos com produções onde a "homossexualidade vem se apresentando de outra forma, com filmes que se mostram afinados com os discursos construídos no interior dos movimentos sociais ou dos grupos intelectuais das chamadas minorias sexuais" (LOURO, 2008, p. 87).

A relação entre estereótipo, estigma e cultura fez com que se exercesse uma batalha contra uma imagem negativa do homossexual nos filmes da atualidade. Indivíduos estigmatizados estão frequentemente expostos a ameaças diretas e indiretas a sua autoestima. "Estereótipos de que os 
homossexuais são inferiores, que possuem defeitos de caráter moral, são mantidos tanto por instituições sociais (tais como família, escola, Igreja e Estado) como pelos meios de comunicação de massa em geral" (NUNAN, JABLONSKI, FÉRES-CARNEIRO, 2003, p. 255). E acrescentam, "homossexuais que internalizam estas crenças podem se sentir inferiores aos heterossexuais e incapazes de alcançar objetivos que contradigam o preconceito" (NUNAN, JABLONSKI, FÉRESCARNEIRO, 2003, p.255).

No filme, Alex se lembra de uma cena da infância na qual sente atração pelos amigos ao tomar banho com eles e logo é rechaçado pelos amigos como gay. O preconceito que se internaliza na infância percorre toda sua vida e traz prejuízos significativos ao indivíduo. Nunan, Jablonski, Féres-Carneiro (2003, p. 256) relatam em seu estudo que

\begin{abstract}
o preconceito internalizado se apresenta em um contínuo que vai desde questionamentos sobre seu próprio valor como indivíduo até o ódio por si mesmo, estando correlacionado também com depressão, baixa autoestima, vergonha, culpa, medo, desconfiança, insegurança, ansiedade, queixas psicossomáticas, sentimentos de solidão, frustração, isolamento social, dificuldade de estabelecer e manter relacionamentos amorosos, violência doméstica, comportamento sexual de risco, abuso de álcool e drogas, transtornos alimentares, e comportamento ou ideação suicida.
\end{abstract}

Alex, no filme, demonstra comportamentos de culpa, vergonha, medo, abuso de álcool e drogas, quando entra em contato com sua realidade homossexual. Sente dificuldades para manter relações sexuais e a partir do beijo em Elliot. Ou seja, a agressividade em seus comportamentos é vista com grande evidência.

Diante desse cenário, Costa, Lopes, Souza e Patel (2001, p. 218) afirmam que

os adolescentes aprendem e disseminam informações inadequadas e preconceitos que, somados ao comportamento onipotente característico da adolescência, contribuem para que tanto a família e a escola como os profissionais de saúde podem contribuir para que adolescentes vivenciem a sexualidade e suas relações afetivas de forma satisfatória e sem riscos, vinculada ao respeito mútuo e sem discriminação de gênero.

Partindo da perspectiva da educação audiovisual da sexualidade, desenvolvida por Silva $(2015,2020)$, que estabelece uma proposta metodológica de análise ao estudo de imagens e sons, em seu guia, Silva (2020) propõe elementos para nortear o docente a encontrar elementos que corroborarão nas intencionalidades do material analisado, neste caso, o filme "Alex Strangelove".

Em seu item 12, o autor propõe pensar "que relações fazer entre esse material/produto"? e nos elenca questionamentos importantes para essa discussão/reflexão: 
Atreladas as análises das temáticas do material, deve-se propor em uma análise o quê se espera dele. Afinal, sendo ele um produto de qualidade ou não, que contribua ou não com aquilo que está sendo exibido, o mesmo está disponível e precisa muitas vezes ser ressignificado. Assim, deve-se pensar: a) para que seja efetivado o compromisso de uma Educação Sexual na escola, este programa/produto destaca sua importância na compreensão das dimensões técnica, estética, política e ética?; b) que elementos de conteúdos efetivamente podem ser extraídos? Seria este programa/produto adequado para uma Educação Sexual na escola?; c) que discursos e representações culturais e sociais estão em jogo nesse/nesses material/materiais? Há modelo de gênero normativos nos personagens? As representações reforçam estereótipos ou possibilitam discussões para o desenvolvimento de diretrizes e princípios filosóficos, éticos e políticos emancipatórios? e; d) De que forma este programa/produto poderia ser ressignificado, atribuindo a ele novos sentidos e novas concepções? (SILVA, 2020, p. 365).

No que se refere às dimensões técnica, estética, política e ética deste item do guia, Silva (2015) aponta que devem ser levados em consideração na dimensão técnica se o material apresenta uma estrutura formal, sistematizada e científica dos conteúdos apresentados ou se estão pautados em afirmações do senso comum. Já na dimensão estética, se refere à sensibilidade e a beleza da sexualidade não mais como algo feio, sujo e vulgar, mas de que maneira a temática é vista e apresentada no material. O autor nos alerta ainda de que cabe a nós, educadores, ressignificar essa visão negativa da sexualidade para uma vivência positiva e saudável da mesma (SILVA, 2020).

No que diz respeito à dimensão política, Silva propõe reflexões acerca do material. Afinal, esse material assume o compromisso quanto à participação ativa frente à luta na construção de uma Educação Sexual emancipada? E, consequentemente, se na dimensão ética, é possível identificar no material analisado um compromisso de "nos levar a uma reflexão/discussão sobre o porquê e para que a ensinamos, [se ele] propõe uma discussão a partir do replanejamento de nossas ações, possibilitando diálogos sobre igualdade de gênero e, principalmente, o respeito às diversidades sexuais, por exemplo” (SILVA, 2020, p. 366).

Portanto, uma forma de educar sexualmente os adolescentes e minimizar os preconceitos, seria a formação de professores, pois através da reflexão sobre as representações sociais construídas na história, chegar-se-ia em uma sexualidade natural e livre das opiniões do senso comum (ALEXANDRINO, 2009). No mais, o mesmo autor afirma que, caso os indivíduos não se preocupassem em conhecer as causas e origens da homossexualidade, mas considerassem o outro como único e singular, seria possível conviver com cada comportamento que é representado por ele.

\section{Considerações finais}

Esse estudo nos convida a perceber que a formação, tanto inicial quanto a continuada em Educação Sexual, é de fundamental importância para que se possibilite pensar/refletir com vistas a um olhar mais natural e amoroso da sexualidade. 
Através de recursos pedagógicos, é possível refletir, discutir e problematizar sobre diversos assuntos, desprendendo-se de mitos, preconceitos e tabus que, muitas vezes, levam o indivíduo a muitas dificuldades emocionais.

Logo, pensar sobre o filme analisado é proporcionar aos graduandos um novo olhar para a diversidade sexual, pois a obra descontrói a orientação sexual enquanto opção, projetando em seu personagem principal, Alex, parte de nosso desejo. Afinal, “a homossexualidade é uma vivência sexual que precisa obter novos significados e sentidos, sem a negação e o silenciamento" (ESPERANÇA, et. al., 2015).

Com uma temática emergente e um roteiro leve, bastante característico das comédias românticas, o filme apresenta ainda uma visão divertida dos problemas reais, tornando-se agradável e divertido de assistir, o que favorece sua inserção em sala de aula.

Nesse contexto, o professor estabelece uma ótima estratégia ao se permitir utilizar instrumentos que levem o conhecimento de formas mais reflexivas para os alunos, sempre com o intuito de alcançá-los no seu universo, formando-os como cidadãos mais éticos e críticos, principalmente no que concerne à sexualidade.

\section{Referências}

ALEXANDRINO, R. A suposta homossexualidade. Dissertação (mestrado) Universidade Estadual de Campinas, Faculdade de Educação, Campinas, SP, 2009. Disponível em: http://www.repositorio.unicamp.br/handle/REPOSIP/251623.

BARBOSA J. P. S. A produção de significados em pôsteres de filmes queer: diálogos entre a Análise Crítica do Discurso, os estudos da tradução e a identidade de gênero. Re-Unir, v. 5, nº 1, p. 197-217, 2018.

COSTA, M. C. O., LOPES, C. P. A., SOUZA, R. P., PATEL, B. N. Sexualidade na adolescência: desenvolvimento, vivência e propostas de intervenção. Jornal de Pediatria, Vol. 77, Supl. 2, 2001.

ESPERANÇA, A. C., SILVA, I. R., NEVES, A. L. M., \& SILVA, F. P. P. Sentidos e significados de homossexualidade para discentes de cursos de licenciaturas. Perspectivas En Psicología, 12(2), 32-40. Disponível em: http://200.0.183.216/revista/index.php/pep/article/view/4

FERNANDO, P. O "Estranho" mundo de Alex Strangelove. Pipoca com pequi. 1 jul.2018. Disponível em: < https://pipocacompequi.tumblr.com/post/175425268784/o-estranho-mundo-de-alexstrangelove $>$. Acesso em: 28 março 2021.

FIGUEIRÓ, M. N. D. Formação de educadores sexuais: adiar não é mais possivel. Londrina: Eduel, 2014.

FIGUEIRÓ, M. N. D. Educação Sexual: saberes essenciais para quem educa. Curitiba: CRV, 2018.

FISCHER, R. M. B. Mídia, máquinas de imagens e práticas pedagógicas. Rev. Bras. Educ. [online]. 2007, vol.12, n.35, pp.290-299 
KIPNISI, L. Contra o amor. Tradução: Ryta Vinagre. $3^{\text {a }}$ ed. Rio de Janeiro: Record, 2012.

LEÃO, A. M. C. Estudo analítico-descritivo do curso de pedagogia da Unesp-Araraquara quanto a inserção das temáticas de sexualidade e orientação sexual na formação de seus alunos. Tese (Doutorado em Educação Escolar) - Faculdade de Ciências e Letras, Universidade Estadual Paulista, Araraquara, SP, 2009.

LOURO, G. L. Cinema e sexualidade. Revista Educação e Realidade. 33(1): 81-98, Jan- Jun, 2008.

MOTTA, D. G.; NUNES, I. M. L. Sexualidade, formação docente e currículo escolar: abordagem Maranhense. Revista Cocar, Edição Especial n² 2, p. 164-181, Ago-dez., 2016.

NASCIMENTO, M. L.; CHIARADIA, C. F. A retirada da orientação sexual do currículo escolar: regulações da vida. Sisyphus Journal of education, v. 5, p. 101-116, 2017.

NASCIMENTO, G. C. M.; SCORSOLINI-COMIN, F. A Revelação da Homossexualidade na Familia: Revisão Integrativa da Literatura Científica. Trends Psychol., Ribeirão Preto, v. 26, n. 3, p. 15271541, Sept. 2018.

NUNAN, A., JABLONSKI, B., FÉRES-CARNEIRO, T. O preconceito sexual internalizado por homossexuais masculinos. Interação Psicológica., 14 (2), 255-262. Rio de Janeiro, RJ.

RODRIGUES, A. R. F., \& SALLES, G. D. Anais II Simpósio Gênero e Políticas Públicas. Londrina, PR, 2011.

SILVA, R. D. Educação audiovisual da sexualidade: uma proposta metodológica para análise e estudo de imagens e sons. Travessias, Cascavel, v. 14, n. 1, p. 354-370, abr. 2020.

SILVA, R. D. Educação Audiovisual da Sexualidade: olhares a partir do Kit Anti-Homofobia. Tese (Doutorado em Educação Escolar). Faculdade de Ciências e Letras, Universidade Estadual Paulista, Araraquara-SP, 2015. 